\title{
A Novel Self-Tuning Fuzzy Logic-Based PID Controllers for Two- Axis Gimbal Stabilization in a Missile Seeker
}

\author{
S. Senthil Kumar $(D)$ and G. Anitha \\ Department of Aerospace Engineering, Division of Avionics, Madras Institute of Technology, Chennai 600044, India \\ Correspondence should be addressed to S. Senthil Kumar; senthil.avionics@gmail.com
}

Received 6 August 2020; Revised 20 December 2020; Accepted 24 December 2020; Published 13 January 2021

Academic Editor: Paolo Castaldi

Copyright (c) 2021 S. Senthil Kumar and G. Anitha. This is an open access article distributed under the Creative Commons Attribution License, which permits unrestricted use, distribution, and reproduction in any medium, provided the original work is properly cited.

\begin{abstract}
Tracking a target is an essential function of a seeker for missiles. The target tracking mechanism of a seeker consists of gimbals, mounted with gyroscopes, and an antenna or some other energy receiving devices such as radar, infrared (IR), or laser. Stabilization of such a gimbal is necessary for any guided missile to maintain the tracking device always pointing towards the target. For the stabilization of the gimbal system, several control methods have been employed for making the gimbal to follow an input rate command by eliminating all the gimbal disturbances. Here, a new self-tuning fuzzy logic-based proportional, integral, derivative (PID) controller is introduced for the stabilization of a two-axis gimbal for a manoeuvring guided missile. The proposed control method involves tuning the gains of the PID controller based on the fuzzy logic rule bases considering the missile body rotation. The performance of the stabilization loops has been verified through MATLAB simulations for fuzzy logic-based PID controller compared with the conventional PID controller. The simulation results show the response of the gimbal system with stabilization loops met the control requirements with fuzzy PID controllers but not with conventional PID controllers.
\end{abstract}

\section{Introduction}

The important function of an inertial stabilization system in pointing and tracking systems is to provide the target motion measurements and to track the target with a sensor. The majority of tracking systems utilize a gimballed tracker for tracking a fixed or moving target. A stabilization system is used for the gimballed tracker to continuously track the target. The stabilization system continuously maintains the tracking sensor's line of sight (LOS) toward the target by isolating the sensor from operating environmental disturbances.

Stabilization of the tracking sensors (such as antennas or telescope) is usually achieved by placing the antenna in a two-axis gimbal, with a two-axis rate sensor placed on the inner gimbal [1]. The gimbal axis is actuated by a dc motor. The angular speed or rotation rate of the gimbal axis sensed by the rate gyro is compared with an input rate command. The difference between the gimbal rate (or LOS rate) and the input rate (called the rate error) is supplied to a controller from which a control signal is generated to drive the dc motor which produces a required torque to turn the gimbal to follow the rate command. Thus, the stabilization loop in target tracking forms a control system in which the purpose of the controller is to make the rate error as zero when the gimbal following the rate command.

As the gimbal system is attached to a base or vehicle body, the control system has to isolate the tracking sensor (or antenna) from base motion. The overall control system for the two-axis gimbal can be constructed with two stabilization loops as shown in Figure 1, where inner (elevation) and outer (azimuth) gimbals correspond to pitch and yaw axes, respectively. In the stabilization loop, a dc motor requires to produce an amount of torque proportional to the control signal input from the controller. The control of LOS inertial stabilization systems is a complex problem because of the precise requirement of providing accurate target tracking and pointing in the dynamic operating environment and the presence of cross-coupling between the two gimbal axes in the system. 


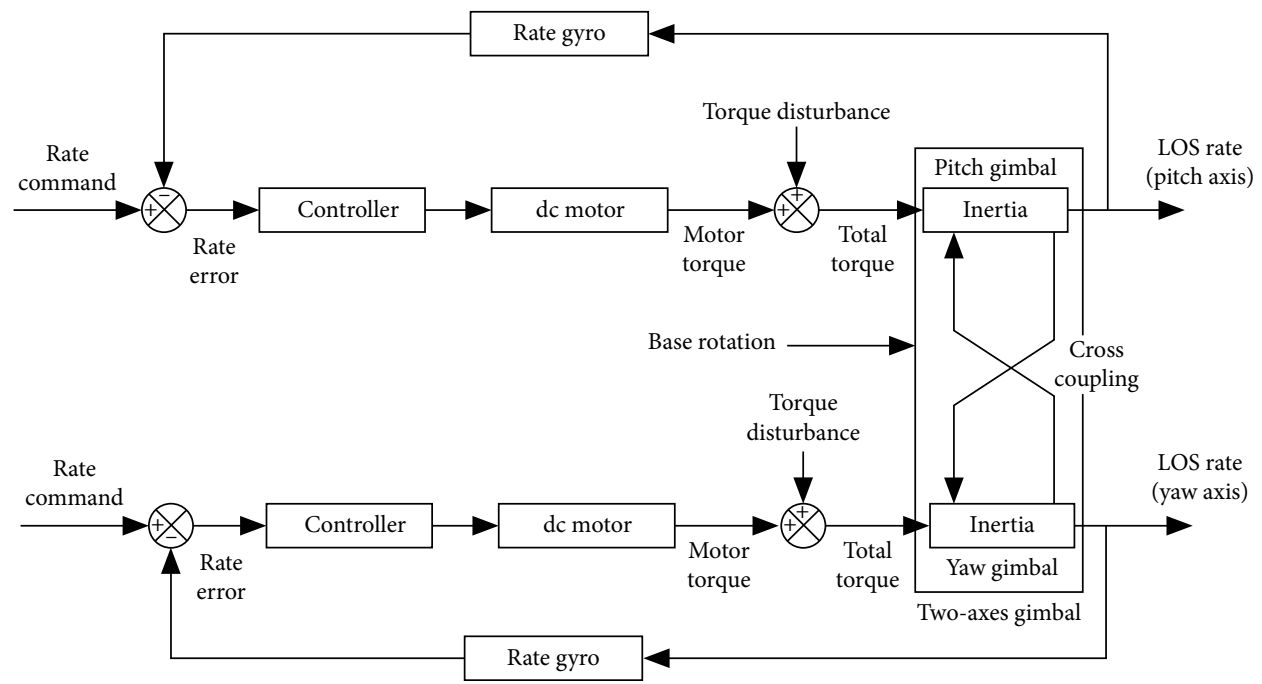

Figure 1: Two-axis gimbal with stabilization loops.

The research on gimbal kinematics and its inertial stabilization was carried out by numerous researchers. In [1-3], the complete equation of motion for a two-axis gimbal has been derived with more detailed explanations of its kinematics and dynamics, but the stabilization of gimbal with the controller through simulation or experimental validation was not carried out. Many types of research have been made on gimbal stabilization through simulation work with many controllers. In [4], a sliding-mode control technique was proposed for a two-axis gimbal system with identical and decoupled azimuth and elevation channels. In [5], a proportional-double integral $\left(\mathrm{PI}^{2}\right)$ controller with lead compensator $\left(\mathrm{PI}^{2} \mathrm{~L}\right.$ controller $)$ has been proposed for stabilization of the direct-drive gimballed platform and demonstrated the performance of stabilization loop using simulation and experimental results. In [6], a proxy-based sliding-mode control has been implemented in a two-axis gimbal line-of-sight stabilization. In [7], a proportional-integral (PI) controller for stabilizing the twoaxis gimbal has been designed and the performance of the PI controller was validated through MATLAB simulations. In [8], an adaptive fractional-order sliding mode controller has been designed to stabilize the two-axis gimbal with the torque disturbance effects and demonstrated the performance of the controller through numerical simulations. In $[9,10]$, a linear, quadratic Gaussian (LQG) algorithm has been adopted in the LOS stabilization. More recently, in [11], a hybrid control method with an incomplete derivative PID (IDPID) controller has been proposed for stabilizing an optoelectronic seeker platform, and in [12], an extended state observer-based adaptive supertwisting sliding-mode controller was presented for stabilization of laser seeker platform. Beyond the conventional control techniques, some modern control methods such as robust control [13-15], variable structure control (VSC) [16], and H-infinity control [17] were also employed in lineof-sight stabilization platforms.

In recent years, the fuzzy logic control method has been largely extended. It improves the performance of the control system with better adaptability for nonlinear dynamics with uncertainties [18, 19]. When the accurate mathematical model of the system under control is not available, the fuzzy logic is most suitable for the rapid dynamic environment and complex control problems [20,21]. Comparing the Takagi Sugeno- (T-S-) based and Mamdani-based fuzzy logic controllers, most of the nonlinear systems are employing the $\mathrm{T}$ $S$ fuzzy model [22]. For complex environments where the system parameters change, the controller is required to tune its gain automatically, and therefore, an adaptive fuzzy control can be used in such cases [19]. An adaptive-neuro fuzzy inference system (ANFIS) and a fuzzy logic-based controller have been presented in [21-25]. Performance analysis of PID, ANFIS, and hybrid-PID ANFIS controllers has been made for brushless dc motor's speed control in [26]. In this paper, a fuzzy logic-based self-tuned PID controller is introduced in a two-axis gimbal system by considering crosscoupling between azimuth and elevation channels, the mass unbalances, and the base (missile) motion. The controller gains are tuned for a dynamic environment based on the fuzzy logic rule bases. The control requirements here are mainly to attain better transient and steady-state responses for a step input command with a faster response without any overshoot and zero steady-state error.

\section{Two-Axis Gimbal System Model}

The two-axis gimbal configuration considered in this paper is shown in Figure 2. The system consists of a two-axis gimbal arrangement on which the tracking sensor (antenna) is mounted. A dc motor is attached to the gimbal pivot with the help of frictionless bearings, and the rate gyro is mounted on the inner gimbal. The gimbal platform is attached to a base (here, a missile body) which is subjected to motion. The rate gyro senses the gimbal rotation rate, thus the LOS rate of the tracking sensor. The stabilization system will make the LOS rate to zero; thus, it helps in pointing the tracking sensor towards a target point.

2.1. Model of Gimbal. The gimbal system consists of two inertial axes-yaw (outer gimbal) and pitch (inner gimbal) - and 


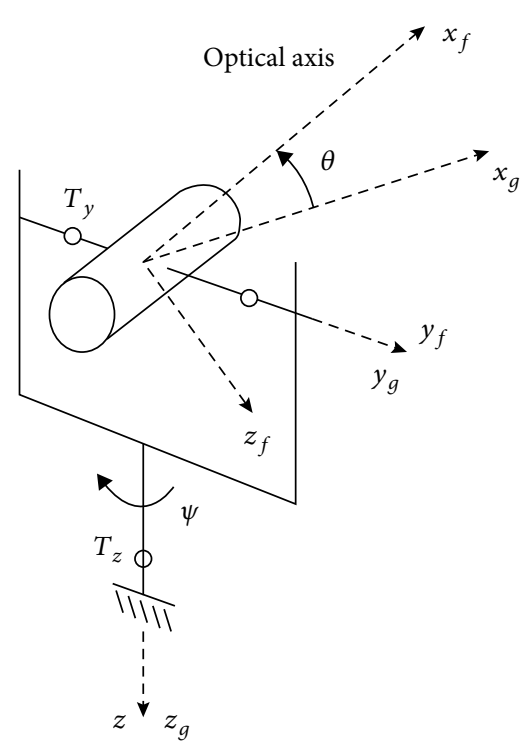

Figure 2: Two-axis gimbal system configuration.

is shown in Figure 2. An antenna can be placed on the inner gimbal. To describe the tracking sensor (antenna) axis, the following reference frames are used: a base body-fixed frame $B$ with axes, a frame $F$ fixed to the inner gimbal (pitch), and a frame $G$ fixed to the outer gimbal (yaw). $x_{f}, y_{f}$, and $z_{f}$ and $x_{g}$, $y_{g}$, and $z_{g}$ are the pitch and yaw gimbal frame axes, respectively. The $x_{f}$-axis coincides with the antenna axis. The $z$ and $z_{g}$-axes coincide and are pointing downwards. The center of rotation is in the frame origin, which is considered to be the same point for all three frames.

Since the antenna is placed in the inner gimbal, there are two coordinate transformations required-(i) the body-fixed frame $B$ into the outer yaw gimbal frame $G$ by a positive angle of rotation $\psi$ about the $z$-axis and (ii) the yaw gimbal frame $G$ into the inner pitch gimbal frame $F$ by a positive angle of rotation $\theta$ about the $y_{g}$-axis. Thus, frame $B$ coincides with frame $G$ for $\psi=0$. The frame $B$ is transformed into frame $G$ by a transformation matrix $T_{G B}$, and the frame $G$ is transformed into frame $F$ by a transformation matrix $T_{F G}$ and is given by

$$
\begin{gathered}
T_{G B}=\left[\begin{array}{ccc}
\cos \psi & \sin \psi & 0 \\
-\sin \psi & \cos \psi & 0 \\
0 & 0 & 1
\end{array}\right], \\
T_{F G}=\left[\begin{array}{ccc}
\cos \theta & 0 & -\sin \theta \\
0 & 1 & 0 \\
\sin \theta & 0 & \cos \theta
\end{array}\right] .
\end{gathered}
$$

The angular velocities of the frames $B, F$, and $G$, respectively, are given by

$$
\begin{gathered}
\omega_{B}=\left[\begin{array}{l}
p \\
q \\
r
\end{array}\right], \\
\omega_{F}=\left[\begin{array}{l}
p_{f} \\
q_{f} \\
r_{f}
\end{array}\right], \\
\omega_{G}=\left[\begin{array}{l}
p_{g} \\
q_{g} \\
r_{g}
\end{array}\right] .
\end{gathered}
$$

The components $p_{f}, q_{f}$, and $r_{f}$ and $p_{g}, q_{g}$, and $r_{g}$ are related by

$$
\begin{gathered}
{\left[\begin{array}{l}
p_{g} \\
q_{g} \\
r_{g}
\end{array}\right]=\left[\begin{array}{ccc}
\cos \psi & \sin \psi & 0 \\
-\sin \psi & \cos \psi & 0 \\
0 & 0 & 1
\end{array}\right]\left[\begin{array}{l}
p \\
q \\
r
\end{array}\right]+\left[\begin{array}{l}
0 \\
0 \\
\dot{\psi}
\end{array}\right],} \\
{\left[\begin{array}{c}
p_{f} \\
q_{f} \\
r_{f}
\end{array}\right]=\left[\begin{array}{ccc}
\cos \theta & 0 & -\sin \theta \\
0 & 1 & 0 \\
\sin \theta & 0 & \cos \theta
\end{array}\right]\left[\begin{array}{l}
p_{g} \\
q_{g} \\
r_{g}
\end{array}\right]+\left[\begin{array}{l}
0 \\
\dot{\theta} \\
0
\end{array}\right] .}
\end{gathered}
$$

When substituting Equation (3) into Equation (4), the inertial angular rate of the antenna in the inner gimbal axis is given by

$$
\begin{aligned}
{\left[\begin{array}{l}
p_{f} \\
q_{f} \\
r_{f}
\end{array}\right]=\left[\begin{array}{c}
(p \cos \psi+q \sin \psi) \cos \theta-(r+\dot{\psi}) \sin \theta \\
-p \sin \psi+q \cos \psi+\dot{\theta} \\
(p \cos \psi+q \sin \psi) \sin \theta+(r+\dot{\psi}) \cos \theta
\end{array}\right] } \\
=\left[\begin{array}{c}
p_{g} \cos \theta-r_{g} \sin \theta \\
q_{g}+\dot{\theta} \\
p_{g} \sin \theta+r_{g} \cos \theta
\end{array}\right] .
\end{aligned}
$$

And the inertial rate of the outer gimbal is given by:

$$
\left[\begin{array}{l}
p_{g} \\
q_{g} \\
r_{g}
\end{array}\right]=\left[\begin{array}{c}
p \cos \psi+q \sin \psi \\
-p \sin \psi+q \cos \psi \\
r+\dot{\psi}
\end{array}\right] .
$$

For deriving the equations of motion for the gimbal, the gimbal is regarded as a rigid body. Now, the inertia matrix of the inner gimbal is denoted by 


$$
J_{F}=\left[\begin{array}{ccc}
J_{f x} & D_{x y} & D_{x z} \\
D_{x y} & J_{f y} & D_{y z} \\
D_{x z} & D_{y z} & J_{f z}
\end{array}\right],
$$

and the inertia matrix of the outer gimbal is denoted by

$$
J_{G}=\left[\begin{array}{lll}
J_{g x} & d_{x y} & d_{x z} \\
d_{x y} & J_{g y} & d_{y z} \\
d_{x z} & d_{y z} & J_{g z}
\end{array}\right],
$$

where

$J_{f x}, J_{f y}, J_{f z}=$ moment of inertia of the inner gimbal ;

$J_{g x}, J_{g y}, J_{g z}=$ moment of inertia of the outer gimbal ;

$D$ and $d=$ product of inertia of respective gimbals

According to $[1,2]$, the equation of motion for the pitch (inner) gimbal is given by

$$
\begin{aligned}
J_{f y} \dot{q}_{f}= & T_{y}+\left(J_{f z}-J_{f x}\right) p_{f} r_{f}+D_{x z}\left(p_{f}^{2}-r_{f}^{2}\right) \\
& -D_{y z}\left(\dot{r}_{f}-p_{f} q_{f}\right)-D_{x y}\left(\dot{p}_{f}+q_{f} r_{f}\right),
\end{aligned}
$$

where

$J_{f y}=$ total moment of inertia of the gimbal about pitch axis ;

$T_{y}=$ motor torque output about the pitch axis ;

$$
\begin{gathered}
\left(J_{f z}-J_{f x}\right) p_{f} r_{f}+D_{x z}\left(p_{f}^{2}-r_{f}^{2}\right)-D_{y z}\left(\dot{r}_{f}-p_{f} q_{f}\right) \\
-D_{x y}\left(\dot{p}_{f}+q_{f} r_{f}\right)=T_{D}=\text { disturbance torque }
\end{gathered}
$$

Expanding Equation (10), using Equations (5) and (6) with further simplification, the equation of motion of inner pitch axis gimbal is given by

$$
\begin{aligned}
J_{f y} \dot{q}_{f}= & T_{y}+\left(J_{f z}-J_{f x}\right) p_{f} r_{f}+D_{x z}\left(p_{f}^{2}-r_{f}^{2}\right) \\
& -\left(D_{y z} \cos \theta-D_{x y} \sin \theta\right)\left(\dot{r}_{g}-p_{g} q_{g}\right) \\
& \left.-\left(D_{x y} \cos \theta+D_{y z} \sin \theta\right)\left(\dot{p} \cos \psi+\dot{q} \sin \psi+q_{g}\left(r_{g}+\dot{\psi}\right)\right)\right\} .
\end{aligned}
$$

The equation of inner pitch gimbal given by Equation (10) is represented as a block diagram as shown in Figure 3.

From Figure 3, it is clear that the inputs to the gimbal platform are the motor torque and the disturbance torque, and the output is the angular velocity of the gimbal which is sensed by the rate gyro for stabilization. Equation (12) is used in the pitch gimbal mathematical model.

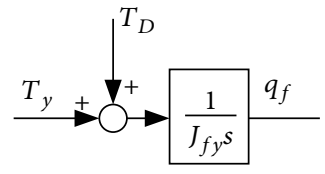

FiguRE 3: Block diagram of pitch (inner) gimbal.

The equation of motion for the outer yaw axis gimbal is given by [1]

$$
\begin{aligned}
J_{g z} \dot{r}_{g}= & T_{z}+\left(J_{g x}-J_{g y}\right) p_{g} q_{g}-d_{x y}\left(p_{g}^{2}-q_{g}^{2}\right) \\
& -d_{x z}\left(\dot{p}_{g}-q_{g} r_{g}\right)-d_{y z}\left(\dot{q}_{g}+p_{g} r_{g}\right) .
\end{aligned}
$$

However, as the inner pitch gimbal is placed on the outer gimbal, the angular momentum of the total gimbal system is the sum of the angular momentum of the inner (pitch) and outer (yaw) gimbals. After some algebraic calculations and simplifications, the equation of motion of yaw axis gimbal is given by

$$
J_{g} \dot{r}_{g}=T_{z}+T_{d 1}+T_{d 2}+T_{d 3}
$$

where

$J_{g}=$ total moment of inertia of the gimbal about yaw $\left(z_{g}\right)$ axis

$T_{z}=$ motor torque output about the yaw axis

$T_{d 1}+T_{d 2}+T_{d 3}=T_{d}=$ disturbance torques for yaw gimbal

$$
\begin{gathered}
T_{d 1}=\left[J_{g x}+J_{f x} \cos ^{2} \theta+J_{f z} \sin ^{2} \theta\right. \\
\left.+D_{x z} \sin (2 \theta)-\left(J_{g y}+J_{f y}\right)\right] p_{g} q_{g}, \\
T_{d 2}=-\left[d_{x z}+\left(J_{f z}-J_{f x}\right) \sin \theta \cos \theta+D_{x z} \cos (2 \theta)\right]\left(\dot{p}_{g}-q_{g} r_{g}\right) \\
-\left(d_{y z}+D_{y z} \cos \theta-D_{x y} \sin \theta\right)\left(\dot{q}_{g}+p_{g} r_{g}\right) \\
\left.-\left(d_{x y}+D_{x y} \cos \theta+D_{y z} \sin \theta\right)\left(p_{g}^{2}-q_{g}^{2}\right)\right\},
\end{gathered}
$$

$$
\begin{aligned}
T_{d 3}= & \ddot{\theta}\left(D_{x y} \sin \theta-D_{y z} \cos \theta\right) \\
& +\dot{\theta}\left[\left(J_{f x}-J_{f z}\right)\left(p_{g} \cos (2 \theta)-r_{g} \sin (2 \theta)\right)\right. \\
& +2 D_{x z}\left(p_{g} \sin (2 \theta)+r_{g} \cos (2 \theta)\right) \\
& \left.\left.+\left(D_{y z} \sin \theta+D_{x y} \cos \theta\right)\left(q_{f}+q_{g}\right)-J_{f y} p_{g}\right]\right\} .
\end{aligned}
$$

From Equations (14)-(20), the block diagram of the yaw gimbal is shown in Figure 4. The specifications of the gimbal considered in this paper are given in Table 1. The complete mathematical model used in the simulation of the two-axis gimbal system is shown in Figure 5. 


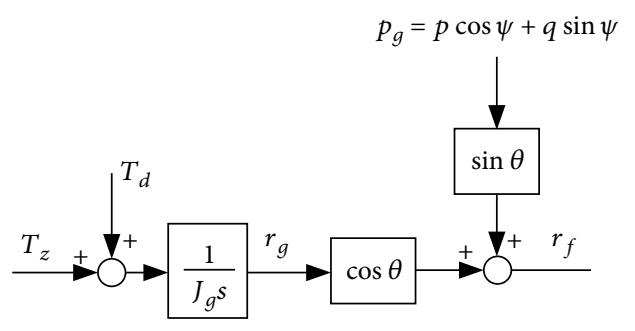

FIGURE 4: Block diagram of yaw (outer) gimbal.

TABLE 1: Gimbal specifications.

\begin{tabular}{lcc}
\hline Parameter & Value & Unit \\
\hline Inner gimbal mass & 1.23 & $\mathrm{~kg}$ \\
Outer gimbal mass & 0.35 & $\mathrm{~kg}$ \\
Mass imbalance & $7 \times 10^{-6}$ & $\mathrm{~g} \cdot \mathrm{cm}$ \\
Load (gimbal) inertia & $6.3 \times 10^{-3}$ & $\mathrm{~kg} \cdot \mathrm{m}^{2}$ \\
\hline
\end{tabular}

2.2. Model of DC Motor. The purpose of the dc motor is to rotate the gimbal by generating a required torque. The shaft of the motor is attached to the gimbal pivot through bearings. The block diagram of the dc motor (transfer function model) is shown in Figure 6.

In Figure 6, " $V_{a}$ " represents the applied voltage across the armature circuit, " $I_{a}$ " represents the current flowing through the armature circuit, " $T_{m}$ " represents the torque developed by the motor, and " $\omega$ " represents the angular velocity of the motor shaft. The specifications of the dc motor considered in this paper are given in Table 2. From the specifications of the dc motor and simplifying the block diagram of the $\mathrm{dc}$ motor model, the transfer function of the $\mathrm{dc}$ motor is obtained as

$$
G_{\text {motor }}(s)=\frac{24637.68}{s^{2}+1500 s+20942} .
$$

2.3. Model of Rate Gyroscope. The purpose of the rate gyroscope (gyro) is to generate a feedback signal for the stabilization loop by sensing the gimbal rate of rotation so that the controller will drive the gimbal to follow an input rate command. The specifications of the rate gyro considered in this paper are given in Table 3. From the specifications of rate gyro, the transfer function of rate gyro, $G_{\text {gyro }}(s)$ is given by

$$
G_{\text {gyro }}(s)=\frac{2500}{s^{2}+70 s+2500}
$$

\section{Fuzzy Logic-Based PID Controller}

One of the widely used controllers in the industry is the wellknown PID controller. But it is not well suited for systems with nonlinear dynamics and uncertainties. For such cases, the gains of the controller need to be tuned manually, and it is not possible for systems with faster response. Hence, there is a need for some means to tune the gains of the controller automatically. In [27], the tuning problem of digital
PID parameters for a dc motor controlled via the controller area network has been investigated. In the proposed controller, a fuzzy logic rule base is formed to tune the controller gains based on an error $e(t)$ and its rate of change $\mathrm{d} e(t) / \mathrm{d} t$, where $e(t)$ is the difference between the input rate command and the rate gyro output. Hence, the system controller is a self-tuned fuzzy logic-based PID controller. The general structure of the fuzzy logic-based PID controller is shown in Figure 7.

The stabilization system consists of two types of a controller-PID controller and fuzzy logic controller (FLC). For the PID section, a conventional PID controller is used, and its control signal is given by

$$
u_{c}=K_{p} e(t)+K_{i} \int e(t) d t+K_{d} \frac{d e(t)}{d t}
$$

where $K_{p}, K_{i}$, and $K_{d}$ are the proportional, integral, and derivative gains, respectively. A fuzzy inference in FLC is used to tune the PID controller parameters by making a nonlinear transfer from the $e(t)$ and $\mathrm{d} e(t) / \mathrm{d} t$ to the PID gains. The structure of FLC consists of four main units: fuzzification, fuzzy rule base, fuzzy inference, and defuzzification. The complete unit of FLC is shown in Figure 8.

The fuzzification process generates a fuzzy value from a real scalar value using various types of fuzzifier, called membership function (MF). An MF defines the mapping between each point in the input space and a membership value, usually between 0 and 1 . There are many MFs available in fuzzy logic. Out of those, the simplest and most commonly used MFs are the triangular membership function (trimf) and trapezoidal membership function (trapmf) [28]. In this paper, the trimf function is used. The behaviour of the fuzzy logic control system is determined by the rules available in the rule base. A fuzzy inference system (FIS) uses fuzzy set theory for mapping inputs to outputs. Internal representations of data in a fuzzy system are usually fuzzy sets. FISs can process the inputs according to the prespecified rules using fuzzy arithmetic and generate the outputs as real values. Two FISs are well known, the Mamdani and the Sugeno. In this paper, Mamdani-based FIS is used with 25 rules and 49 rules to tune the PID controller gains for stabilizing the two-axis gimbal. As a final step, the defuzzification process converts the fuzzy inference results into a single number (crisp output) based on a fuzzy set. The two commonly known defuzzification methods are employed for Mamdani-based fuzzy controllers - the mean of maxima (MoM) method and the center of area (CoA) or centroid method, in which the latter one is used in this proposed work.

3.1. Proposed Controller Structure. In literature, several configurations of fuzzy PID and non-PID controllers have been proposed. For traditional fuzzy PID controllers, the design of rule base is more difficult because of three inputs and three-dimension rule base, and in such cases, fuzzy PD type or PI type controllers can be employed. But the PD type controllers which are improving the transient response will not eliminate the steady-state error, and the PI type controllers used for eliminating the steady-state error will not give better 


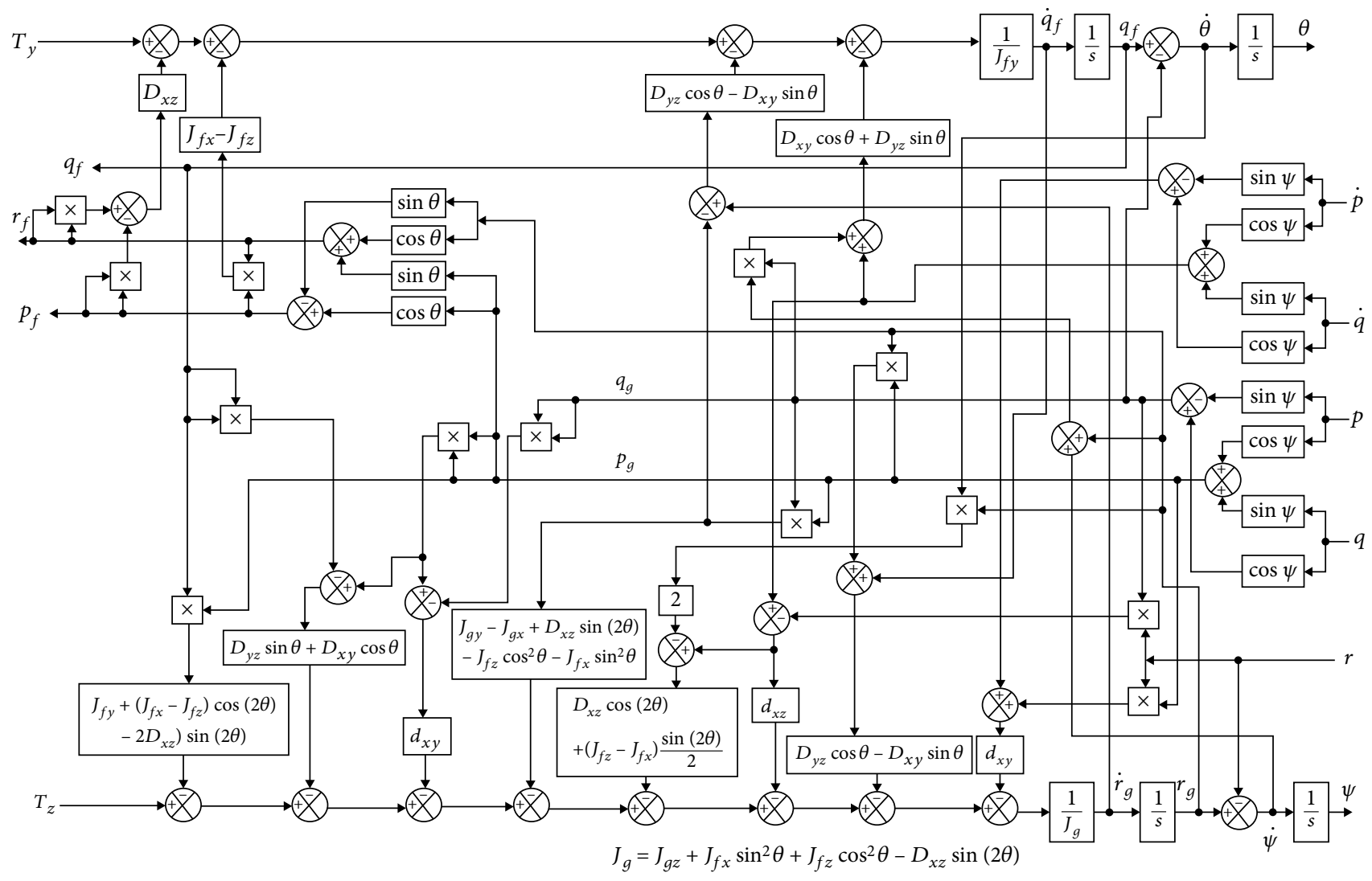

FIGURE 5: Complete two-axis gimbal kinematics model.

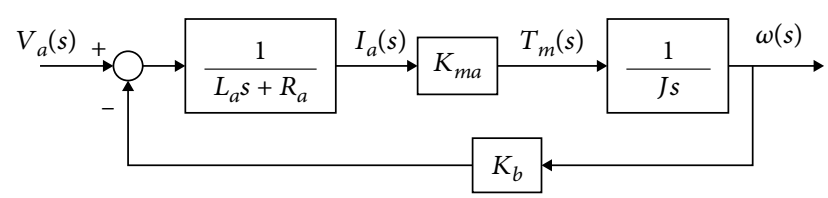

FIgURE 6: Block diagram of armature controlled dc motor.

TABLE 2: DC motor specifications.

\begin{tabular}{lcc}
\hline Parameter & Value & Unit \\
\hline Nominal voltage & 27 & volts \\
No load speed & 303 & $\mathrm{rpm}$ \\
Motor torque constant, $K_{m a}$ & 0.85 & $\mathrm{Nm} / \mathrm{A}$ \\
Armature resistance, $R_{a}$ & 4.5 & $\mathrm{Ohm}$ \\
Armature inductance, $L_{a}$ & 0.003 & $\mathrm{H}$ \\
Back emf constant, $K_{b}$ & 0.85 & $\mathrm{volts} /(\mathrm{rad} / \mathrm{s})$ \\
Moment of inertia of rotor, $J$ & 0.0017 & $\mathrm{~kg} \cdot \mathrm{m}^{2}$ \\
\hline
\end{tabular}

transient response for higher-order systems [28]. Thus, for getting the advantages of PD and PI type controllers, it is desirable to combine these controllers to form a fuzzy PID type controller. Because of the difficulty in selecting a range for input and output membership functions, it is necessary to scale, or normalize, the range for input/output variables [28].
TABLE 3: Rate gyro specifications.

\begin{tabular}{lcc}
\hline Parameter & Value & Unit \\
\hline Input rate & \pm 150 & $\mathrm{deg} / \mathrm{s}$ \\
Scale factor & 100 & $\mathrm{mV} /(\mathrm{deg} / \mathrm{s})$ \\
Bandwidth & 400 & $\mathrm{~Hz}$ \\
Natural frequency & 50 & $\mathrm{~Hz}$ \\
Damping ratio & 0.7 & - \\
\hline
\end{tabular}

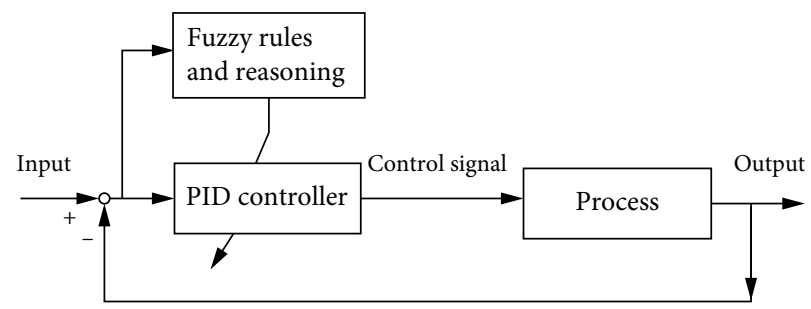

Figure 7: Fuzzy logic-based PID Controller.

A proposed fuzzy PID type controller consists of normalization and denormalization steps which include input and output scaling factors. A crisp input value can be converted into a normalized value using an input scaling factor to maintain the input value within the operating range. From the normalized range of the output, an output scaling factor converts the defuzzified crisp output into an actual physical output. The Simulink model of the proposed fuzzy PID 


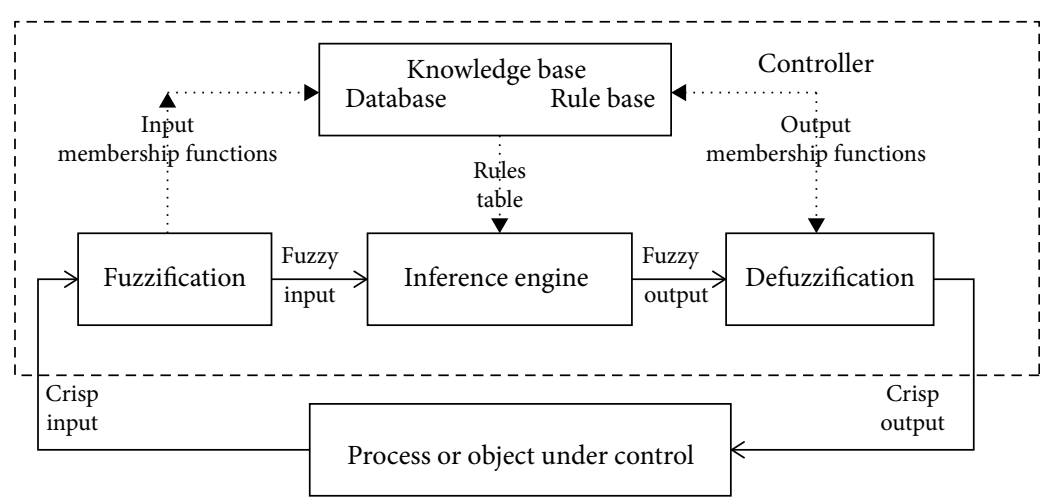

FIgURE 8: Components of fuzzy logic controller.

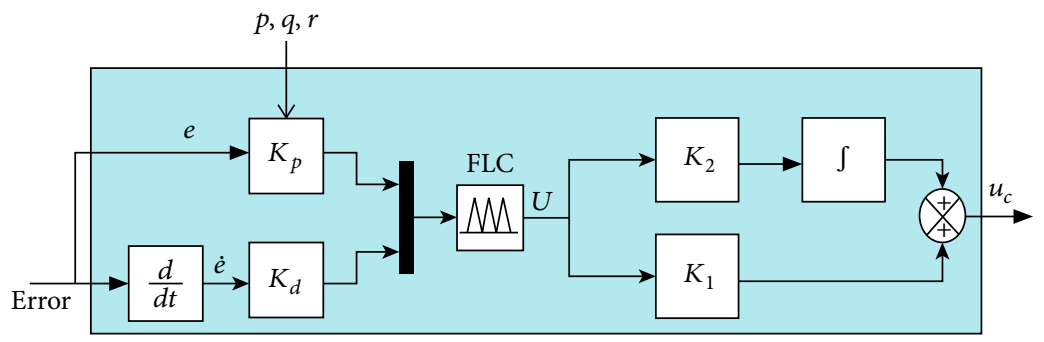

Figure 9: Simulink model of proposed fuzzy PID controller.

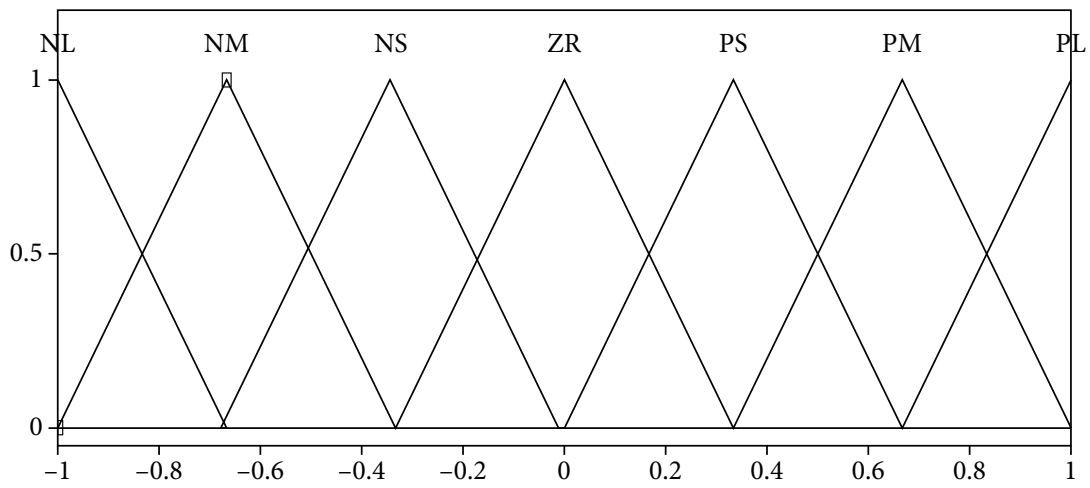

FIGURE 10: Membership function for input and output variables.

controller with input and output scaling factors is shown in Figure 9, where $K_{p}$ and $K_{d}$ are the input scaling factors for error $e(t)$ and its rate of change, and $K_{1}$ and $K_{2}$ are the output scaling factors. The input scaling factor, $K_{p}$, depends on the base motion ( $q$ and $r$ ), and the equations to determine $K_{p}$ for azimuth and elevation axes are given by

$$
\text { For elevation axis : } K_{p}=0.803 \times q \text {, }
$$

$$
\text { For azimuth axis : } K_{p}=0.6278 \times r \text {. }
$$

The input and output variables of FLC are related by

$$
U=K_{p} e+K_{d} \dot{e}
$$

And the output of the fuzzy PID controller is

$$
\begin{aligned}
u_{c} & =K_{1} U+K_{2} \int U d t=K_{1} K_{p} e+K_{1} K_{d} \dot{e}+K_{2} K_{p} \int e d t+K_{2} K_{d} e \\
& \left.=\left(K_{1} K_{p}+K_{2} K_{d}\right) e+K_{2} K_{p} \int e d t+K_{1} K_{d} \dot{e}\right\}
\end{aligned}
$$

where $\left(K_{1} K_{p}+K_{2} K_{d}\right) e, K_{2} K_{p} \int e d t$, and $K_{1} K_{d} \dot{e}$ are proportional, integral, and derivative terms, respectively.

3.2. Controller Design. In the fuzzification process, the triangular membership function is chosen for error, $e(t)$, rate of change of error, $\mathrm{d} e(t) / \mathrm{d} t$, and $U$ variables with seven linguistic variables defined, namely, negative large (NL), negative medium (NM), negative small (NS), zero (ZR), positive small (PS), positive medium (PM), and positive large (PL) and are 
shown in Figure 10. The normalized variation range [min, $\max$ ] of $e(t)$ is described by Equations (28)-(34).

$$
\begin{gathered}
\mu_{N L}(e(t))=\frac{-0.6666-e(t)}{0.3334}, \quad-1 \leq e(t) \leq-0.6666, \quad(28) \\
\mu_{N M}(e(t))= \begin{cases}\frac{1+e(t)}{0.3334}, \quad-1 \leq e(t) \leq-0.6666, \\
\frac{-0.3334-e(t)}{0.3332}, \quad-0.6666 \leq e(t) \leq-0.3334,\end{cases}
\end{gathered}
$$

$\mu_{N S}(e(t))= \begin{cases}\frac{e(t)+0.6772}{0.3332}, & -0.6772 \leq e(t) \leq-0.344 \\ \frac{-0.01058-e(t)}{0.33342}, & -0.344 \leq e(t) \leq-0.01058\end{cases}$

$$
\begin{aligned}
& \mu_{Z R}(e(t))= \begin{cases}\frac{e(t)+0.3334}{0.3334}, & -0.3334 \leq e(t) \leq 0, \\
\frac{0.3332-e(t)}{0.3332}, & 0 \leq e(t) \leq 0.3332,\end{cases} \\
& \mu_{P S}(e(t))= \begin{cases}\frac{e(t)}{0.3332}, \quad 0 \leq e(t) \leq 0.3332, \\
\frac{0.6668-e(t)}{0.3336}, & 0.3332 \leq e(t) \leq 0.6668,\end{cases}
\end{aligned}
$$

$$
\mu_{P M}(e(t))=\left\{\begin{array}{l}
\frac{e(t)-0.3332}{0.3336}, \quad 0.3332 \leq e(t) \leq 0.6668 \\
\frac{1-e(t)}{0.3332}, \quad 0.6668 \leq e(t) \leq 1
\end{array}\right.
$$

$$
\mu_{P L}(e(t))=\frac{e(t)-0.667}{0.333}, \quad 0.667 \leq e(t) \leq 1 .
$$

The normalized range of $\mathrm{d} e(t) / \mathrm{d} t$ is similar to Equations (28)-(34), except that $\dot{e}(t)$ is used in place of $e(t)$. Here, the max-min method of fuzzy inference is used, and the output control variable $U$ can be determined from the centroid method. The value of input and output scaling factors is determined through an online process based on the base motion (here, missile body rotations) where the gimbal is attached. According to Equations (24) and (25), the value $K_{p}$ depends on missile body pitch rate, $q$, and yaw rate, $r$.

\begin{tabular}{|c|c|c|c|c|c|c|c|c|}
\hline & \multicolumn{7}{|c|}{$\mathrm{d} e(t) / \mathrm{d} t$} \\
\hline & & NL & NM & NS & ZR & PS & PM & PL \\
\hline \multirow{7}{*}{$e(t)$} & NL & $\mathrm{NL}$ & $\mathrm{NL}$ & $\mathrm{NL}$ & NL & $\mathrm{NM}$ & NS & $\overline{\mathrm{ZR}}$ \\
\hline & NM & NL & NL & NL & NM & NS & ZR & PS \\
\hline & NS & NL & NL & NM & NS & $\mathrm{ZR}$ & PS & $\mathrm{PM}$ \\
\hline & ZR & NL & NM & NS & $\mathrm{ZR}$ & PS & PM & PL \\
\hline & PS & NM & NS & ZR & PS & $\mathrm{PM}$ & PL & PL \\
\hline & $\mathrm{PM}$ & NS & ZR & PS & $\mathrm{PM}$ & PL & PL & PL \\
\hline & PL & ZR & PS & PM & PL & PL & PL & PL \\
\hline
\end{tabular}
The values of other input and output scaling factors used in the simulation are given in Table 4 .
TABLE 4: Scaling factor values in fuzzy PID.

\begin{tabular}{lccc}
\hline Gimbal axis & $K_{d}$ & $K_{1}$ & $K_{2}$ \\
\hline Elevation (pitch) & 0.02 & 0.09 & 10 \\
Azimuth (yaw) & 0.04 & 0.33 & 19 \\
\hline
\end{tabular}

TABLE 5: Fuzzy PID rule base for input and output variables.

Depending on process and controller type, the formation of fuzzy rules varies. The rule base is chosen based on controller properties, nonlinear disturbances, dc motor characteristics, and gimbal payload. An approach for forming the rule base is as follows: when the difference between the desired output and the system output is too large, the error value needs to be reduced so that the system output reaches the desired value rapidly; thus, the desired rule base is if $e(t)$ is $\mathrm{PL}$ and $\mathrm{d} e(t) / \mathrm{d} t$ is $\mathrm{ZR}$, then the control variable $U$ is selected to be PL. If the error $e(t)$ is ZR and $\mathrm{d} e(t) / \mathrm{d} t$ is nonzero, then $U$ should not be zero (for example, if $e$ is ZR and $\mathrm{d} e / \mathrm{d} t$ is $\mathrm{NL}$, then $U$ is $\mathrm{NL})$. When the system output reaches the desired value, both $e(t)$ and $\mathrm{d} e / \mathrm{d} t$ are zero; thus, there is no need for control input; therefore, $U$ should be selected to be ZR. The complete rule base contains 49 rules based on the above approach and is shown in Table 5. For analysing the performance of fuzzy PID controller with 49-rule Mamdani method, another rule base is considered with 25 rules similar to rule base with 49 rules except for the linguistic variables NM and PM.

\section{Simulation Results}

The behaviour of the two-axis gimbal system with and without controllers has been analysed in MATLAB/Simulink. The two-axis gimbal consists of coupled elevation and azimuth stabilization loops. The inertia matrices for the two gimbal axes used in the simulation are

$$
\begin{aligned}
& \text { Elevation axis : } J_{F}=\left[\begin{array}{ccc}
0.001 & -0.002 & -0.004 \\
-0.002 & 0.0006 & -0.001 \\
-0.004 & -0.001 & 0.006
\end{array}\right] \text {, } \\
& \text { Azimuth axis: } J_{G}=\left[\begin{array}{ccc}
0.003 & -0.002 & -0.004 \\
-0.002 & 0.0003 & -0.001 \\
-0.004 & -0.001 & 0.0003
\end{array}\right] \text {. }
\end{aligned}
$$




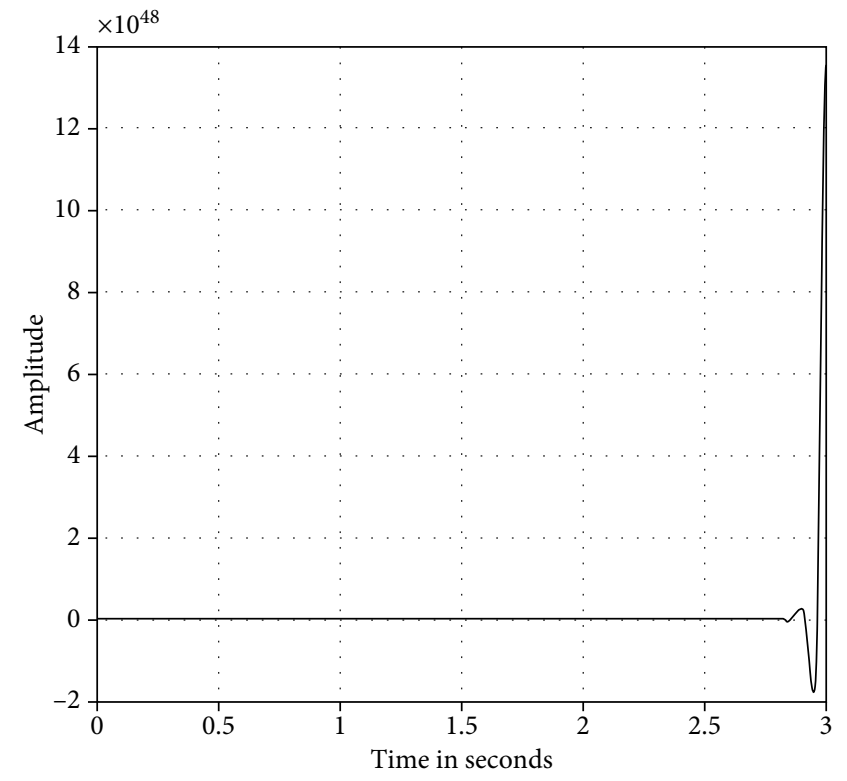

(a)

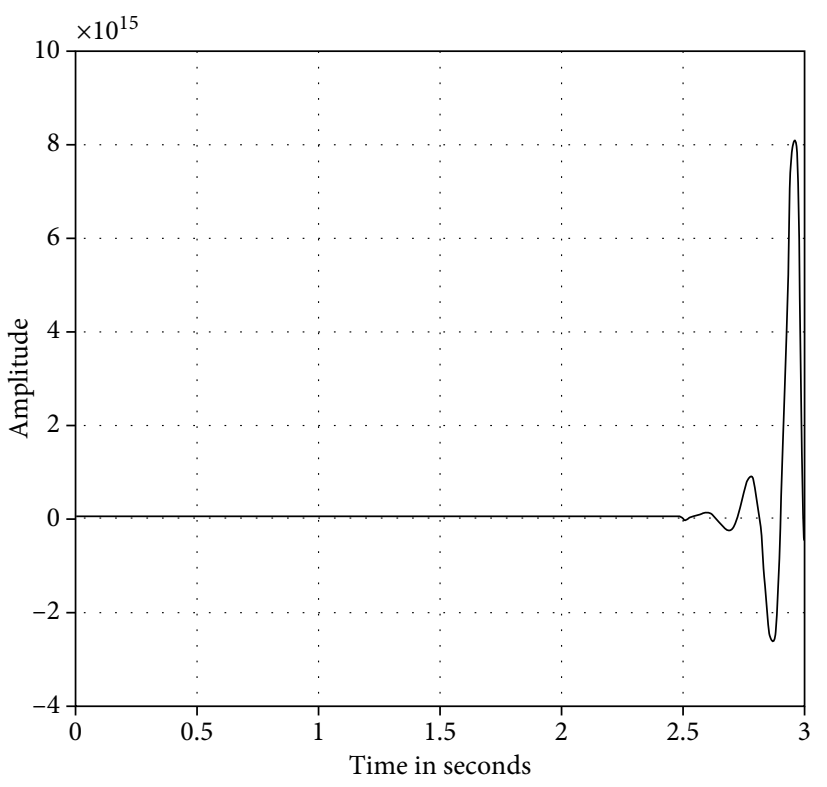

(b)

FIGURE 11: Response of gimbal rate without controller for a missile rotation of $10 \mathrm{deg} / \mathrm{s}$ - elevation axis (a); azimuth axis (b).

TABLE 6: Gains of conventional PID controllers used in simulation of traditional PID gimbal stabilization loops.

\begin{tabular}{lccc}
\hline Gimbal axis & $\begin{array}{c}\text { Proportional } \\
\text { gain }\end{array}$ & $\begin{array}{c}\text { Integral } \\
\text { gain }\end{array}$ & $\begin{array}{c}\text { Derivative } \\
\text { gain }\end{array}$ \\
\hline $\begin{array}{l}\text { Elevation } \\
\text { (pitch) }\end{array}$ & 0.01196 & 0.00582 & 0.0009 \\
Azimuth (yaw) & 0.0942 & 0.0458 & 0.09 \\
\hline
\end{tabular}

The complete simulation model is developed in MATLAB Simulink. The response of the two-axis gimbal system without a stabilization controller is shown in Figure 11. For analysing the performance of the proposed fuzzy PID controller, its response is compared with the traditional PID controller with selected gain values given in Table 6 . The performance of the stabilization loops for the two-axis gimbal system with conventional PID controller and fuzzy logic-based PID controller is validated through MATLAB simulations with step input and various missile body rotation rates.

The behaviour of the gimbal system with stabilization loops has been verified with various values of missile rotation rate ranging from 5 to $30 \mathrm{deg} / \mathrm{s}$. The comparison graphs showing the performance of stabilization loops with conventional PID controllers and fuzzy logic-based PID controller with 25 rule base and 49 rule base for a given rate command are shown in Figures 12 and 13 with missile body rotation rate of $10 \mathrm{deg} / \mathrm{s}$. The performance specifications of the gimbal system with conventional PID controllers and fuzzy logic PID controller for various missile rotation rates are summarized in Table 7 . The result shows better control performance for FLC-based PID controller than the conventional PID controller and overcomes the problems of nonlinearity, dis- turbances due to cross-coupling between the gimbal axis and missile body rotation.

\section{Conclusions}

A two-axis gimbal model for a missile seeker was proposed considering the factors of missile motion, dynamic mass imbalance, and coupled gimbal axes. For that gimbal system, a self-tuning fuzzy logic-based PID controller was proposed to stabilize the gimbal LOS rate for its stabilization loop. The controllers have been designed with the proposed fuzzy logic-based rules to obtain the control output. The performance of stabilization loops has been verified through MATLAB simulations and found that the fuzzy logic-based PID controller performs with better accuracy, i.e., zero overshoot and zero steady-state error, and settles faster than traditional PID controllers, thereby improving the performance of the gimbal in case of nonlinearities. From the results, the following observations have been made. First, the response of the gimbal system for a rate command is faster with traditional PID controllers than the fuzzy logic-based PID controllers, but the response is settled faster with fuzzy logicbased PID controllers than the traditional PID controllers. Second, the response of the gimbal system for missile rotation rate of 5-30 deg/s shows an overshoot of nearly $6-20 \%$ with the conventional PID controllers, whereas there is no overshoot in the gimbal system response with the fuzzy logic-based PID controllers. Finally, the steady-state responses of the gimbal system with the conventional PID controllers have an error of around $0.1-22 \%$ for the missile rotation rate of $5-30 \mathrm{deg} / \mathrm{s}$, whereas there is no error in the steady-state from the gimbal system with the fuzzy logicbased PID controllers. Further, the performance of the gimbal system is greatly improved with fuzzy PID controllers 


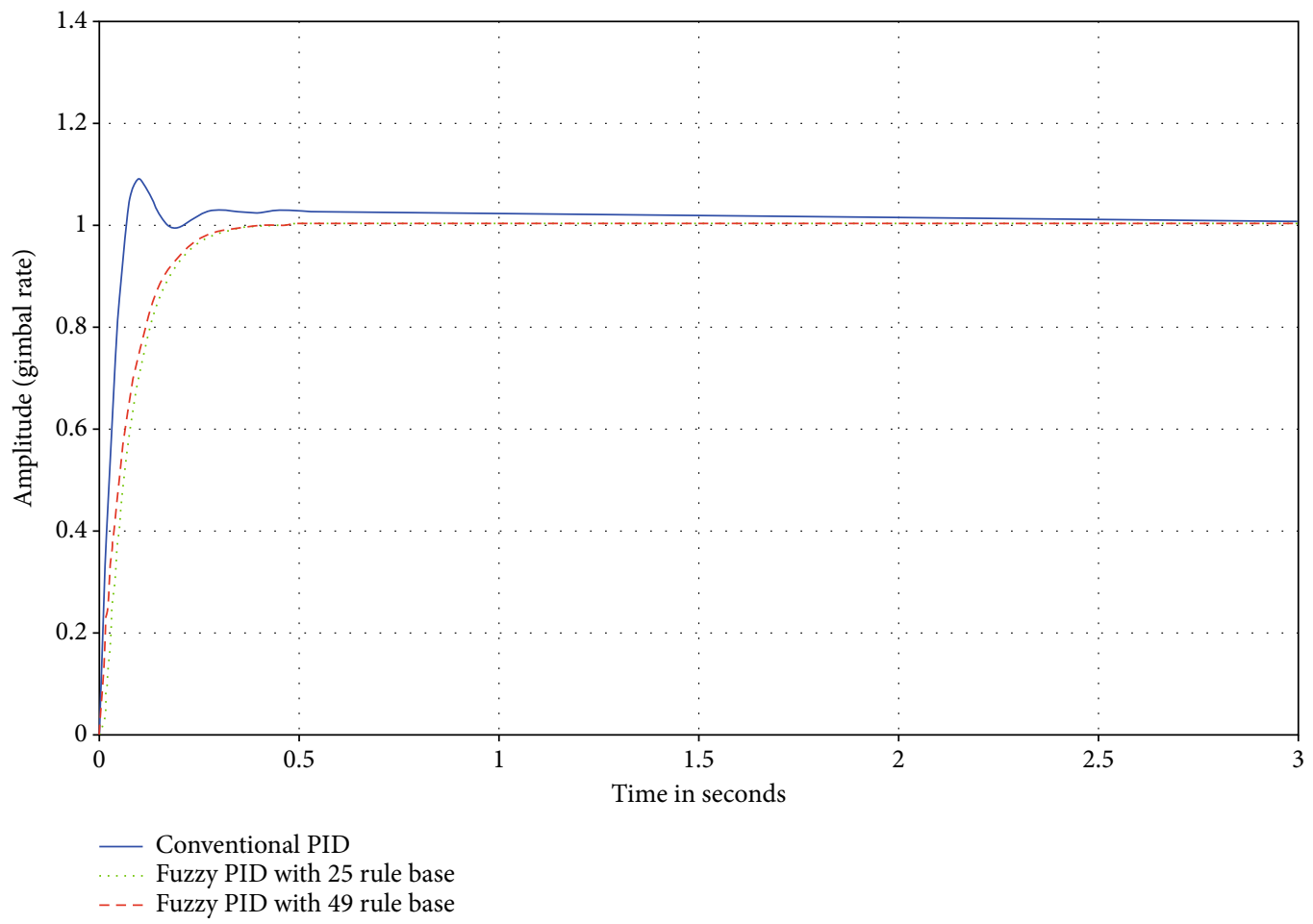

Figure 12: Step response of elevation gimbal with conventional and fuzzy PID controllers for a missile rotation of $10 \mathrm{deg} / \mathrm{s}$.

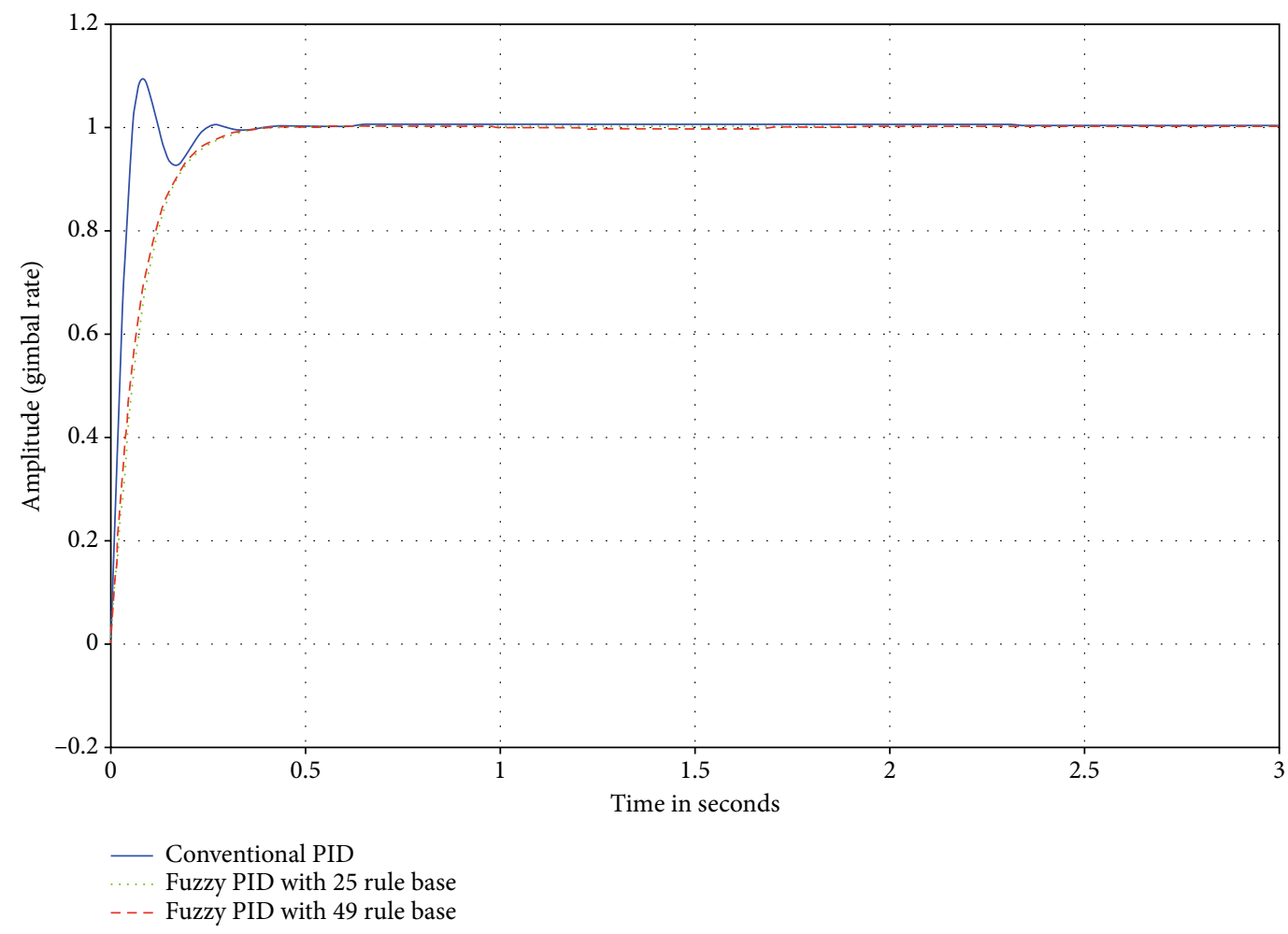

Figure 13: Step response of azimuth gimbal with conventional and fuzzy PID controllers for a missile rotation of $10 \mathrm{deg} / \mathrm{s}$. 
TABle 7: The response of stabilization loops with conventional PID and fuzzy PID type controllers.

\begin{tabular}{|c|c|c|c|c|c|c|c|}
\hline $\begin{array}{l}\text { Missile } \\
\text { rotation } \\
(p, q, r)\end{array}$ & Specification & $\begin{array}{c}\text { Conventional } \\
\text { PID }\end{array}$ & $\begin{array}{c}\text { Elevation axis } \\
\text { Fuzzy PID WITH } \\
25 \text { rule base }\end{array}$ & $\begin{array}{c}\text { Fuzzy PID WITH } \\
49 \text { rule base }\end{array}$ & $\begin{array}{c}\text { Conventional } \\
\text { PID }\end{array}$ & $\begin{array}{c}\text { Azimuth axis } \\
\text { Fuzzy PID WITH } \\
25 \text { rule base }\end{array}$ & $\begin{array}{c}\text { Fuzzy PID WITH } \\
49 \text { rule base }\end{array}$ \\
\hline \multirow{4}{*}{$5 \mathrm{deg} / \mathrm{s}$} & $\begin{array}{l}\text { Rise time } \\
\quad(\mathrm{sec})\end{array}$ & 0.068 & 0.2 & 0.2 & 0.061 & 0.18 & 0.172 \\
\hline & $\begin{array}{l}\text { Overshoot } \\
(\%)\end{array}$ & 6.2 & 0 & 0 & 8.1 & 0 & 0 \\
\hline & $\begin{array}{l}\text { Settling time } \\
\quad(\mathrm{sec})\end{array}$ & 2.4 & 0.33 & 0.31 & 0.41 & 0.23 & 0.2 \\
\hline & $\begin{array}{l}\text { Steady-state } \\
\text { error }\end{array}$ & 0.002 & 0 & 0 & 0.0025 & 0 & 0 \\
\hline \multirow{4}{*}{$10 \mathrm{deg} / \mathrm{s}$} & $\begin{array}{l}\text { Rise time } \\
\quad(\mathrm{sec})\end{array}$ & 0.07 & 0.3 & 0.29 & 0.06 & 0.2 & 0.2 \\
\hline & $\begin{array}{l}\text { Overshoot } \\
(\%)\end{array}$ & 8.8 & 0 & 0 & 9.32 & 0 & 0 \\
\hline & $\begin{array}{l}\text { Settling time } \\
(\mathrm{sec})\end{array}$ & 2.6 & 0.42 & 0.42 & 0.45 & 0.287 & 0.282 \\
\hline & $\begin{array}{c}\text { Steady-state } \\
\text { error }\end{array}$ & 0.0026 & 0 & 0 & 0.003 & 0 & 0 \\
\hline \multirow{4}{*}{$15 \mathrm{deg} / \mathrm{s}$} & $\begin{array}{l}\text { Rise time } \\
\quad(\mathrm{sec})\end{array}$ & 0.1 & 0.33 & 0.3 & 0.0612 & 0.23 & 0.22 \\
\hline & $\begin{array}{l}\text { Overshoot } \\
(\%)\end{array}$ & 12.1 & 0 & 0 & 14.55 & 0 & 0 \\
\hline & $\begin{array}{l}\text { Settling time } \\
(\mathrm{sec})\end{array}$ & 2.9 & 0.44 & 0.4 & 0.63 & 0.3 & 0.29 \\
\hline & $\begin{array}{l}\text { Steady-state } \\
\text { error }\end{array}$ & 0.11 & 0 & 0 & 0.112 & 0 & 0 \\
\hline \multirow{4}{*}{$20 \mathrm{deg} / \mathrm{s}$} & $\begin{array}{l}\text { Rise time } \\
\quad(\mathrm{sec})\end{array}$ & 0.12 & 0.35 & 0.33 & 0.068 & 0.29 & 0.232 \\
\hline & $\begin{array}{l}\text { Overshoot } \\
(\%)\end{array}$ & 13.2 & 0 & 0 & 15.1 & 0 & 0 \\
\hline & $\begin{array}{l}\text { Settling time } \\
\quad(\mathrm{sec})\end{array}$ & 3.1 & 0.47 & 0.425 & 0.66 & 0.39 & 0.38 \\
\hline & $\begin{array}{c}\text { Steady-state } \\
\text { error }\end{array}$ & 0.12 & 0 & 0 & 0.12 & 0 & 0 \\
\hline \multirow{4}{*}{$25 \mathrm{deg} / \mathrm{s}$} & $\begin{array}{l}\text { Rise time } \\
\quad(\mathrm{sec})\end{array}$ & 0.16 & 0.38 & 0.36 & 0.08 & 0.33 & 0.29 \\
\hline & $\begin{array}{l}\text { Overshoot } \\
(\%)\end{array}$ & 16.6 & 0 & 0 & 16.8 & 0 & 0 \\
\hline & $\begin{array}{l}\text { Settling time } \\
\quad(\mathrm{sec})\end{array}$ & 3.6 & 0.49 & 0.44 & 0.73 & 0.44 & 0.42 \\
\hline & $\begin{array}{l}\text { Steady-state } \\
\text { error }\end{array}$ & 0.15 & 0 & 0 & 0.14 & 0 & 0 \\
\hline \multirow{4}{*}{$30 \mathrm{deg} / \mathrm{s}$} & $\begin{array}{l}\text { Rise time } \\
\quad(\mathrm{sec})\end{array}$ & 0.25 & 0.43 & 0.38 & 0.12 & 0.36 & 0.34 \\
\hline & $\begin{array}{l}\text { Overshoot } \\
(\%)\end{array}$ & 20.4 & 0 & 0 & 19.6 & 0 & 0 \\
\hline & $\begin{array}{l}\text { Settling time } \\
(\mathrm{sec})\end{array}$ & 4.4 & 0.56 & 0.51 & 0.78 & 0.53 & 0.49 \\
\hline & $\begin{array}{l}\text { Steady-state } \\
\text { error }\end{array}$ & 0.22 & 0 & 0 & 0.2 & 0 & 0 \\
\hline
\end{tabular}


employing 49 rules than 25 rules for the rule base. Although a lot of control methods have been used widely to improve the performance of the control system, the aim of the proposed fuzzy logic-based PID controller is to tune the controller gains automatically to overcome the missile rotation and also to eliminate the overshoot without much increase in rise time and eliminate the steady-state error in gimbal system response so that the tracking device mounted in the gimbal follow the LOS rate command.

\section{Data Availability}

The data used to support the findings of this study are available from the corresponding author upon request.

\section{Conflicts of Interest}

All authors declare that they have no conflict of interest.

\section{References}

[1] B. Ekstrand, "Equations of motion for a two-axes gimbal system," IEEE Transactions on Aerospace and Electronic Systems, vol. 37, no. 3, pp. 1083-1091, 2001.

[2] A. K. Rue, "Stabilization of precision electrooptical pointing and tracking systems," IEEE Transactions on Aerospace and Electronic Systems, vol. AES-5, no. 5, pp. 805-819, 1969.

[3] A. K. Rue, "Precision stabilization systems," IEEE Transactions on Aerospace and Electronic Systems, vol. AES-10, no. 1, pp. 34-42, 1974.

[4] B. J. Smith, W. J. Schrenk, W. B. Gass, and Y. B. Shtessel, "Sliding mode control in a two-axis gimbal system," in 1999 IEEE Aerospace Conference. Proceedings (Cat. No.99TH8403), pp. 457-470, Snowmass at Aspen, CO, USA, 1999.

[5] Y. S. Kwon, H. Y. Hwang, and Y. S. Choi, "Stabilization loop design on direct drive gimbaled platform with low stiffness and heavy inertia," in 2007 International Conference on Control, Automation and Systems, pp. 320-325, Seoul, South Korea, 2007.

[6] Ö. Hastürk, A. M. Erkmen, and I. Erkmen, "Proxy-based sliding mode stabilization of a two-axis gimbaled platform," in Proceedings of World Congress on Engineering and Computer Science, pp. 370-376, San Francisco, CA, USA, 2011.

[7] M. Abdo, A. R. Vali, A. Toloei, and M. R. Arvan, "Research on the cross-coupling of a two axes gimbal system with dynamic unbalance," International Journal of Advanced Robotic Systems, vol. 10, no. 10, p. 357, 2013.

[8] A. Naderolasli and M. Tabatabaei, "Stabilization of the twoaxis gimbal system based on an adaptive fractional-order sliding-mode controller," IETE Journal of Research, vol. 63, pp. 124-133, 2016.

[9] J. B. William and P. T. Steven, "Optimal motion stabilization control of an electro-optical sight system," in Acquisition, Tracking, and Pointing III, pp. 116-120, Orlando, FL, USA, 1989.

[10] B. Li, D. Hullender, and M. DiRenzo, "Nonlinear induced disturbance rejection in inertial stabilization systems," IEEE Transactions on Control Systems Technology, vol. 6, no. 3, pp. 421-427, 1998.

[11] M. Zhang, H. Liu, H. Zhang, and X. Miao, "A hybrid control strategy for the optoelectronic stabilized platform of a seeker," Optik, vol. 181, pp. 1000-1012, 2019.
[12] M. Zhang, Y. Guan, and W. Zhao, “Adaptive super-twisting sliding mode control for stabilization platform of laser seeker based on extended state observer," Optik, vol. 199, article 163337, 2019.

[13] L. Ho-Pyeong and Y. Inn-Eark, "Robust control design for a two-axis gimbaled stabilization system," in 2008 IEEE Aerospace Conference, pp. 1-7, Big Sky, MT, USA, 2008.

[14] H. Khodadadi, M. R. J. Motlagh, and M. G. Sefidmazgi, "Robust control and modeling a 2-DOF inertial stabilized platform," in International Conference on Electrical, Control and Computer Engineering 2011 (InECCE), pp. 223-228, Pahang, Malaysia, 2011.

[15] C. M. Lin, C. F. Hsu, and Y. J. Mon, "Self-organizing fuzzy learning CLOS guidance law design," IEEE Transactions on Aerospace and Electronic Systems, vol. 39, no. 4, pp. 1144-1151, 2003.

[16] K. K. Tan, T. H. Lee, A. Mamun, M. W. Lee, and C. J. Khoh, "Composite control of a gyro mirror line-of-sight stabilization platform - design and auto-tuning," ISA Transactions, vol. 40, no. 2, pp. 155-171, 2001.

[17] J. A. R. Krishna Moorty, R. Marathe, and V. R. Sule, "Ho control law for line-of-sight stabilization for mobile land vehicles," Optical Engineering, vol. 41, no. 11, pp. 2935-2945, 2002.

[18] C.-Y. Li and W. X. Jing, "Fuzzy PID controller for 2D differential geometric guidance and control problem," IET Control Theory and Applications, vol. 1, no. 3, pp. 564-571, 2007.

[19] S. Tong and Y. Li, "Observer-based fuzzy adaptive control for strict-feedback nonlinear systems," Fuzzy Sets and Systems, vol. 160, no. 12, pp. 1749-1764, 2009.

[20] N. Jamali and S. Amlashi, "Design and implementation of fuzzy position control system for tracking applications and performance comparison with conventional PID," IAES International Journal of Artificial Intelligence (IJ-AI), vol. 1, no. 1, pp. 31-44, 2012.

[21] S. R. Khuntia, K. B. Mohanty, S. Panda, and C. Ardil, "A comparative study of P-I, I-P, fuzzy and neuro-fuzzy controllers for speed control of DC motor drive," International Journal of Electrical and Computer Engineering, vol. 5, no. 5, pp. 714-718, 2011.

[22] J. J. Buckley, "Universal fuzzy controllers," Automatica, vol. 28, no. 6, pp. 1245-1248, 1992.

[23] J. A. R. Krishna Moorty, R. Marathe, and H. Srivastava, "Fuzzy controller for line-of-sight stabilization systems," Optical Engineering, vol. 43, no. 6, pp. 1394-1400, 2004.

[24] K. C. Tan, T. H. Lee, E. F. Khor, and D. C. Ang, "Design and real-time implementation of a multivariable gyro-mirror line-of- sight stabilization platform," Fuzzy Sets and Systems, vol. 128, no. 1, pp. 81-93, 2002.

[25] M. Akar and I. Temiz, "Motion controller design for the speed control of DC servo motor," International Journal of Applied Mathematics and Informatics, vol. 1, no. 4, pp. 131-137, 2007.

[26] H. Tanjung, P. H. Sasongko, and S. Suharyanto, "Performance analysis of hybrid PID-ANFIS for speed control of brushless DC motor base on identification model system," International Journal of Computer and Information Technology, vol. 2, no. 4, pp. 694-700, 2013.

[27] Z. Qi, Q. Shi, and H. Zhang, "Tuning of digital PID controllers using particle swarm optimization algorithm for a CAN-based DC motor subject to stochastic delays," IEEE Transactions on Industrial Electronics, vol. 67, no. 7, pp. 5637-5646, 2020.

[28] L. Reznik, Fuzzy Controllers, Butterworth-Heinemann, Oxford, 1997. 